\title{
A Curriculum Reform in Fluid Mechanics for the Millennial Generation
}

\author{
Alamgir A. Choudhury, Ph.D. ${ }^{1}$, Jorge Rodriguez, Ph.D. ${ }^{2}$ \\ ${ }^{1}$ Western Michigan University, USA, alamgir.choudhury@wmich.edu, Jorge.rodriguez@wmich.edu
}

\begin{abstract}
Learning habit of new generations of students growing up with cell phone, social media and video games are significantly different from that of the educators preparing them for the future workplace. Effectiveness of traditional lecture based class room are questioned by educators, parents, industry and government. In the field of science technology engineering and mathematics (STEM), besides class room teaching method, importance of hands-on learning underscores the need for reform of curriculum. This paper studies need for graduate knowledge and skill in fluid mechanics area and presents an ongoing curriculum reform process. A multi-mode student learning process is developed and course is reformed to support an interactive pedagogical methodology. Beyond current teaching methods, tools are developed to foster a flexible inductive learning through hands-on applications and online learning tools. A multipurpose laboratory equipped with fluid power process, sensors, data acquisition system, and application programs are being developed. A series of laboratory practices based on use of fluid mechanics principles in industrial applications would provide students a strong theoretical foundation on the subject covered in the class, and create opportunity to practice current industrial methods prior to graduation. These practices with industrial processes, sensors, data acquisition hardware, and application programs in the laboratory will enhance technical skills of program graduates. Finally, the project evaluation, assessment, and dissemination process for monitoring and evaluating project activities, outcomes assessment of student learning and feedback for continuous curriculum improvement is presented.
\end{abstract}

Keywords - Hands-on practice, adaptive learning, inductive learning, fluid mechanics, fluid power

Digital Object Identifier (DOI): http://dx.doi.org/10.18687/LACCEI2015.1.1.077

ISBN: 13 978-0-9822896-8-6

ISSN: 2414-6668

$1^{\text {th }}$ LACCEI Annual International Conference: “Engineering Education Facing the Grand Challenges, What Are We Doing?” July 29-31, 2015, Santo Domingo, Dominican Republic DOI: http://dx.doi.org/10.18687/LACCEI2015.1.1.077 


\title{
A Curriculum Reform in Fluid Mechanics for the Millennial Generation
}

\author{
Alamgir A. Choudhury, Ph.D., Jorge Rodriguez, Ph.D. \\ EDMMS Department, Western Michigan University, USA \\ alamgir.choudhury@wmich.edu ,Jorge.rodriguez@wmich.edu
}

\begin{abstract}
Learning habit of new generations of students growing up with cell phone, social media and video games are significantly different from that of the educators preparing them for the future workplace. Effectiveness of traditional lecture based class room are questioned by educators, parents, industry and government. In the field of science technology engineering and mathematics (STEM), besides class room teaching method, importance of hands-on learning underscores the need for reform of curriculum. This paper studies need for graduate knowledge and skill in fluid mechanics area and presents an ongoing curriculum reform process. A multi-mode student learning process is developed and course is reformed to support an interactive pedagogical methodology. Beyond current teaching methods, tools are developed to foster a flexible inductive learning through hands-on applications and online learning tools. A multipurpose laboratory equipped with fluid power process, sensors, data acquisition system, and application programs are being developed. A series of laboratory practices based on use of fluid mechanics principles in industrial applications would provide students a strong theoretical foundation on the subject covered in the class, and create opportunity to practice current industrial methods prior to graduation. These practices with industrial processes, sensors, data acquisition hardware, and application programs in the laboratory will enhance technical skills of program graduates. Finally, the project evaluation, assessment, and dissemination process for monitoring and evaluating project activities, outcomes assessment of student learning and feedback for continuous curriculum improvement is presented.
\end{abstract}

Keywords: Hands-on practice, adaptive learning, inductive learning, fluid mechanics, fluid power

\section{INTRODUCTION}

Compared to earlier generations, millennial, $\mathrm{Y}$ and $\mathrm{Z}$ generations are the most diverse student body in the class room of higher education. Because of ubiquitous use of technology from the childhood, predominant learning mode of these generations has transformed from traditional passive to more active form. While the traditional teaching methodology developed based on passive mode of learning served well in the past, these new generations are gradually becoming detached from the learning methods practiced. They see a sharp contrast between their comfort level of technology and the technology comfort level of their teachers.
In the State of Michigan the manufacturing is the most critical component of the economy and has been contracting due to competition from other parts of the world for more efficient and cost effective products and services. The workplace of engineering and engineering technology program graduates is changing due to increasing global competition, changing demographics and technology, integration of engineering and business function, shrinking product life cycle and environmental awareness. To regain their predominance in the field, manufacturing industries in Michigan need better-educated technical graduates trained in current technology. These graduates are also expected to be equipped with generic engineering skills beyond their area of expertise [2]. In many courses in the engineering technology programs, especially, in the fluid mechanics course, the theoretical learning is impeded by lack of handson practices and exposure to modern problem-solving tools. During last few years, several computer assisted tools [3-6] were developed to enhance student-learning in specific areas. The experience of developing these tools and their outcomes has motivated authors to address the learning deficiency in the current fluid mechanics course. The plan is a comprehensive approach to the problem including curricular reform; adaptation of a multi-mode inductive learning methodology, and continued assessment and improvement of the learning process. It partially adopts the inductive learning model implemented by S. Moor [7]. Inductive approach is a natural way of learning when the subject is completely unknown to the learner, such as how a baby learns by doing and experiencing with the object without instruction. On the other hand deductive approach suits abstract learning when the learner is already familiar with subject or activities do not easily relate to subject. Most engineering and technology classes are taught by using a combination of the two based on the nature of course, student background and the learning objectives. If the learning objectives are not easily realized, the method of learning deserves a close scrutiny [8]. Kolb's experiential learning cycle [9] is widely considered to have addressed learning problems in engineering education. His four steps for complete learning cycle are: abstract conceptualization, active experimentation, concrete experience and reflective observation. The beginning and end can be in any of these

$1^{\text {th }}$ LACCEI Annual International Conference: “Engineering Education Facing the Grand Challenges, What Are We Doing?” July 29-31, 2015, Santo Domingo, Dominican Republic ISBN: 13 978-0-9822896-8-6 ISSN: 2414-6668 
steps depending on the method of teaching. In the current course, we find this cycle is either broken or does not exist. Therefore, we search for feasible activities to complete the learning cycle without overwhelming burden on the students, programs and the institution. Moor [7] adapted the inductive learning method through experimental demonstration, dry-lab thought experiment, and class room teaching through lecture, experiment and problem solving in chemical engineering program. The outcomes have been extremely positive [10]. Hesketh [12] adapted an inductive learning method in junior level fluid mechanics and heat transfer courses and showed that engaging students in hands on activities increase both learning and retention [12]. Our plan is to address learning problem in fluid mechanics based on inductive approach of Moor [7] and Hesketh [12]. The proposed method considers the nature of our program, student body, industry need and past experience with computer assisted problem solving in other classes. Overall goal of the project is to improve student learning by curricular reform and a multimode teaching

The specific objectives are:

1. Identify knowledge and skill requirement in IME3840 (Fluid mechanics and hydraulics) course and reform the curriculum structure.

2. Develop a multipurpose laboratory for application practices necessary in the courses.

3. Develop computer-assisted problem-solving tools for the course.

4. Develop teaching methodology for the course to foster inductive learning through applications, problem solving and theory.

5. Document measures of learning effectiveness to ensure continuous improvement in student learning in long run.

\section{STUDENT LEARNING IN PROGRAMS}

Upon teaching both in engineering and engineering technology programs, one may notice a fundamental shift in student learning mechanisms between the two areas. In most engineering programs, the theoretical learning in class is reinforced with problem solving, laboratory practices and other modes of learning in a progressive manner. Students are expected to be prepared with proper math and science background prior to learning the theoretical basis of a subject. Generally, the majority of the students adjust with this learning mechanism soon after entering an engineering program. On the other hand, in the engineering technology programs, the objective is to prepare students for application-oriented tasks in industry. Naturally, students also expect to learn the applications rather than the detailed theoretical body of knowledge. Several informal surveys current fluid mechanics and hydraulics class have indicated that about half of the students in the class learn their subject differently compared to students in engineering programs. For efficient learning, these students prefer to become familiar with the subject initially through technical applications. In the problem-solving area, the focus is on the methodology rather than the theoretical origin of the subject. Therefore, for these students, the theoretical learning is more effective after they are already familiar with the applications and problem-solving method. These findings underscore the importance of mixed mode instruction in the engineering technology classes for enhancing effectiveness of student learning.

\section{CURRENT PRACTICES}

IME 3840 (Fluid Mechanics and Hydraulics) is a two credit hour theory class on fluid mechanics and hydraulics applications in industry. Student feedback and course assessment data suggest that there is a clear lack of student interest in this class. Established factors contributing to this are:

i. It is lecture only theory class without application in a technology program.

ii. Because of the application expectation, students lack of adequate preparation in math and science at the time they take the class.

iii. A two credit hour course is insufficient to teach a broad subject that requires both theoretical and applied learning.

iv. No follow-up course or project built on student learning is provided.

To enhance its effectiveness, this course requires reform including the introduction of laboratory applications and multimode teaching that introduces application practices, problem solving, and theory to the students in an orderly fashion. Web-based problem solving and simulation to investigate different scenarios will promote student interest in the subject. A redesigned three-credit hour fluid power class would better reinforce theoretical learning in the classroom based on the laboratory practices and problem solving. Besides lessons on industrial fluid power applications, the laboratory will also act as a conduit to introduce use of modern sensors, data acquisition, and control technology to the engineering technology students. The learning in this course will be practiced further in other senior level courses and applied research projects solving industrial problems.

\section{PROPOSED LEARNING METHOD}

After reforming the curricula, teaching methodology in the four courses will be modified to engage the students in an interactive multi-mode learning process. The modes are laboratory practice, computer-assisted problem solving, inclass lecture and analytical problem solving. Initially, simple laboratory practices and demonstrations will expose the students to applications prior to introduction of each theoretical concept in the lecture class. While the students learn the analytical problem solving methods in the class, computer-assisted tools will be available to guide them through the solution. Prior experience with computerassisted tools has shown that this practice engages them in the learning process, generates interest in underlying theory,

13 $^{\text {th }}$ LACCEI Annual International Conference: "Engineering Education Facing the Grand Challenges, What Are We Doing?" July 29-31, 2015, Santo Domingo, Dominican Republic 
and allows students to identify areas of deficiency in their learning. The difference is in engaging them in thinking by exposing them to applications, problem solving, and solution verification beyond the traditional methods of teaching. Education researchers have been studying the effectiveness of various learning philosophy [9], e.g. active versus reflective, sensate versus intuitive, visual versus verbal, global versus sequential in different environments. Our method of combined use of application, problem solving and assessment will engage students in a mixed form of learning. The key is to monitor its effectiveness and adopt with the assessment feedback information until we settle on a superior mode of teaching and student learning cycle (Figure 1).

\section{DESCRIPTION OF LABORATORY}

The proposed development is dual purpose laboratory for both fluid mechanics/hydraulics and thermodynamics courses within the engineering technology programs. It will be equipped with electro-hydraulic and pneumatic process trainers, Feedback temperature and flow process. To monitor the process variables such as pressure, temperature, force/torque, flow rate, position, velocity, acceleration etc, a variety of sensors, transducers and measuring instruments will be utilized. Using laboratory $\mathrm{PC}$ and National Instrument's PXI/SCXI data acquisition hardware, the overall system will be monitored and controlled through open instrumentation network architecture. The objective is to let the student experience from simple fundamental processes to progressively complex industry like systems in the same laboratory.

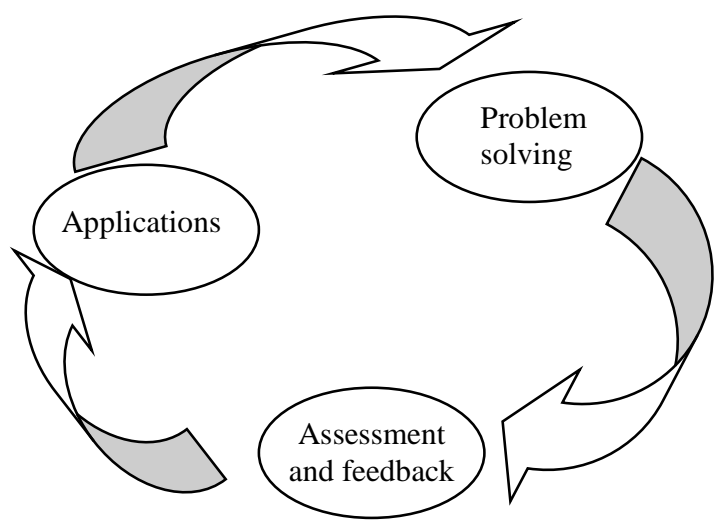

Figure 1. Learning cycle

It also minimizes development and operation cost of the learning system. For in-depth experience in process monitoring, data acquisition, data processing, and the design and development of a practical application, integration of NI hardware and the LabVIEW software with the electrohydraulic, pneumatic, and electro-mechanical equipment will be extremely valuable $[13,14]$. A number of industries employing WMU graduates in the region use similar system in their plants and feel that exposure to such system will familiarize our students with current industrial practices. Beyond the laboratory experiments, live image and process data of selected physical systems will be available for classroom demonstration through the use of wireless web communication infrastructure of the university.

Without existing infrastructure and careful planning, development of such a laboratory can be excessively cost prohibitive. Hydraulic/pneumatic trainer necessary for function of this laboratory are available in current motion control laboratory. They will be utilized along with the remaining components of the processes, sensors and data acquisition hardware to develop a fully functional laboratory necessary to implement the proposed multi-mode learning model in the targeted courses. Use of a blend of process equipment, sensors, and data acquisition hardware from different manufacturers allows open ended extension of the processes. Compared to an integrated overall system from a specific vendor, use of components from different origins allows students to see the problems associated with integration in real life industries and learn the technology in more details. As opposed to a turnkey project, this is also a cost effective method of creating the learning opportunities. The development plan for the overall laboratory setup is shown in Figure 2.

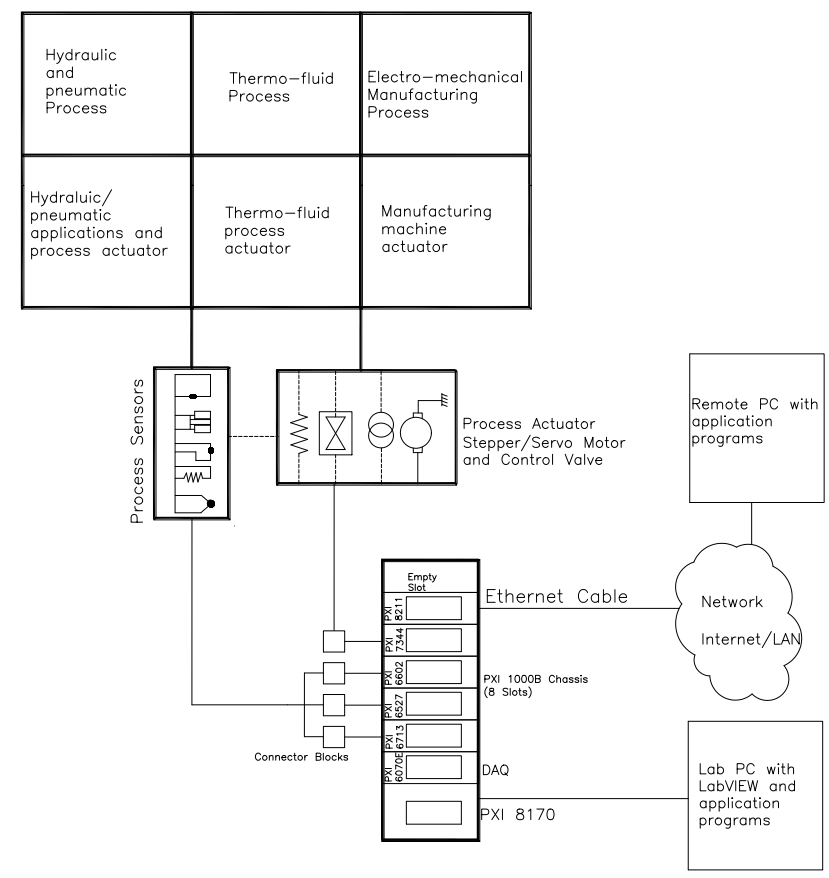

Figure 2. Layout of thermo-fluid laboratory

\section{LABORATORY EXPERIMENTS AND}

\section{PROBLEM SOLVING TOOLS}

The nature of laboratory practices will vary from demonstration of simple physical phenomenon to design and implementation of complex manufacturing task. Each experiment will be designed with the aim of exposing

13 $^{\text {th }}$ LACCEI Annual International Conference: "Engineering Education Facing the Grand Challenges, What Are We Doing?" July 29-31, 2015, Santo Domingo, Dominican Republic 
students to the specific theoretical formulation/principle and corresponding problem solving method taught. The area of laboratory experiments and demonstrations for the class is listed below.

a. Measurement of fluid flow parameters

b. Verification of basic fluid statics principles

c. Investigation of fluid friction principles

d. Application of fluid power for specific force and motion function

e. Design and development of functional fluid power system

f. Operation and control of a fluid power system

g. Efficiency of fluid power system components

Initial demonstrations and hands on practices IME3840 class are designed to engage students in learning the theoretical fundamentals, will be accompanied by simple application programs in Visual Basic and Excel. After students are acquainted with the phenomenon, these application programs will allow them to verify the laboratory results using the analytical equations taught in lecture class. Students will be able to use executable form of the programs though the web and will not require any programming background to use them.

\section{IMPLEMENTATION PLAN}

Implementation of the project will started with redeveloping the curricula of the Fluid Mechanics course based on industry need and other model curricula. It is developed as a three credit junior level (EDDM 3840) course with laboratory practices necessary to assist learning the theoretical topics. Equipment for the laboratory has been procured, installed, tested and calibrated. Laboratory practices were developed and documented for teaching purpose. At the same time web based application programs is developed to assist student with the problem solving methods. Assessment and improvement of the implementation process is an integral part of the project. An online assessment tool is developed to utilize the input from students and the learning tools will be adapted to suit the learning habit of students. Over next several teaching cycles, the curriculum will evolve to match with student learning habit of the millennial generation.

\section{STUDENT LEARNING ASSESSMENT}

Purposes of assessment will be to (a) establish benchmarks against which change and improvement can be measured; (b) determine the effects of the curricular reform activities on student learning; (c) involve a full constituency of those impacted by curricular reform; and (d) document project activities for dissemination and eventual full implementation. The assessment will have both formative and summative components. The plan is framed by key assessment questions related directly to project goals and objectives. Although the primary focus of assessment will be on project results (summative assessment) - impacts on engineering technology students' ability to learn and apply crucial skills - data will also be gathered to help inform project decision-making (formative assessment).

For this project, assessment will begin with benchmarking the current practices and student learning outcomes. While the concerns addressed in this proposal have been well established through several assessment methods - course evaluations, ongoing program evaluation at the department level, industry feedback, and informal student-faculty interaction - formal documentation of student learning based on current practices in the identified courses will be conducted by faculty outside the courses to establish a formal baseline and comparison data for eventual review of reform activities. Methods will include surveys, observations, document review, and interviews with students. Additionally, in order to identify change needed and to support reform, a formal review of changing industry needs will be undertaken during the first phase. Already the technology programs, in concert with program advisory boards, have developed a "skill set" of techniques, knowledge, and abilities our courses should provide students. Industry advisors will match with a skill set of their own, identifying needs and priorities to be addressed by reform. These skills sets will be used in the creation and implementation of assessment activities throughout the reform project.

\section{CONCLUSION}

To fulfill current industry need for students with both theoretical and hands on knowledge, a plan to reform existing fluid mechanics curriculum is presented. The basis for the reform is student, industry and industrial advisory committee feedback. Besides laboratory experience, a multimode teaching/learning methodology and corresponding assessment/evaluation method is presented. It will ensure eventual realization of the reform objectives. The curriculum reform has started from Fall semester of 2013 and will be completed after a learning and assessment cycle of three years.

\section{REFERENCES}

1. California State University - Long Beach, http://www.csulb.edu/divisions/students2/intouch/archives/200708/vol16_no1/01.htm

2. Connor, H; Dench, S; Bates, P., An Assessment of Skill Needs in Engineering, Institute for Employment Studies Report, SD2, Nottingham, UK, 2001.

3. Choudhury, A., Ramrattan, S. and Ikonomov, P., "A web based approach for real time process control", International Journal of Advanced Manufacturing Systems, Vol. 8(2), 2005.

4. Choudhury, A., Ikonomov, P., Keil, M., Ramrattan, S., and Rodriguez, $\mathrm{J}$.; Online experimentation for study of stress and deformation in structural beams, Proceedings of the ASEE 2005 Annual Conference, Portland, OR, June 2005.

5. Choudhury, A., Rodriguez, J., Arif, M. and Keil, M.; Computer Assisted Tools for Stress Analysis of Structural Components in Engineering Technology, Proceedings of the ASEE 2003 Annual Conference, Nashville, TN, June 2003.

13 $^{\text {th }}$ LACCEI Annual International Conference: "Engineering Education Facing the Grand Challenges, What Are We Doing?" July 29-31, 2015, Santo Domingo, Dominican Republic 
6. Choudhury, A; Ochei, C and Rice, R; Simulation for the study of beam deflection in strength of materials. ASEE 2001 Annual Conference Proceeding, Albuquerque, NM, June 2001.

7. Flexible Process Control Laboratory Kits: Teaching Process Control Synthesis, NSF Grant\# 0127231,

http://www.nsf.gov/awardsearch/showAward.do?AwardNumber=012 7231

8. Felder, R. and Silverman, L., "Learning and Teaching Styles in Engineering Education”, Engr. Education, 78(7), 1988.

9. Kolb, D., "Experiential Learning: Experience as the Source of Learning and Development", Prentice-Hall 1984.

10. Moor, S. and Piergiovanni, P., "Experiments in the Classroom: Examples of Inductive Learning with Classroom-Friendly Laboratory Kits", ASEE Annual Conference Proceeding, Nashville, TN, June 2003.

11. Hesketh, R., Farrell, S. and Slater, C., "An Inductive Approach to Teaching Courses in Engineering", ASEE Annual Conference Proceeding, Nashville, TN, June 2003.

12. Deobelin, E., Measurement System: application and design, McGrawHill Inc., NY 1996.

13. Considine, M., Process/Industrial instrumentation and controls handbook, McGraw-Hill Inc., NY 1993.

13 $^{\text {th }}$ LACCEI Annual International Conference: "Engineering Education Facing the Grand Challenges, What Are We Doing?" July 29-31, 2015, Santo Domingo, Dominican Republic 